\title{
Network well-being from a balanced centricity perspective
}

\author{
Fabian Groven \\ Department of Health Services Research, Care and Public Health Research Institute (CAPHRI), \\ Maastricht University, Maastricht, The Netherlands \\ Gaby Odekerken-Schröder \\ Department of Marketing and Supply Chain Management, School of Business and Economics, \\ Maastricht University, Maastricht, The Netherlands, and \\ Sandra Zwakhalen and Fan Hamers \\ Department of Health Services Research, Care and Public Health Research Institute (CAPHRI), \\ Maastricht University, Maastricht, The Netherlands
}

\begin{abstract}
Purpose - This paper aims to explore how tensions and alignments between different actors' needs in a transformative services network affect balanced centricity, which is an indicator of well-being. Balanced centricity describes a situation in which all network actors' interests and needs are fulfilled simultaneously. In such cases, all actors are better off, which increases both individual actors' and overall actor-network well-being.

Design/methodology/approach - The empirical study takes place in nursing homes in which in-bed baths represent co-created service encounters that affect the well-being of focal actors (i.e. patients), frontline service employees (i.e. nurses) and transformative service mediators (i.e. family members), who have potentially competing needs. Using a qualitative, phenomenological approach, the study inductively explores and deductively categorizes actors' personal experiences to gain deep, holistic insights into the service network and its complex web of actor interdependencies.

Findings - The resulting conceptual model of balanced centricity identifies actors' lower-order needs as different manifestations of the psychological needs for autonomy, competence and relatedness. If actors' needs are aligned, their psychological needs can be satisfied, which facilitates balanced centricity. If actors exhibit competing needs though, balanced centricity is impeded.

Practical implications - This study establishes actors' psychological needs as the origin of tensions/alignments in multi-actor networks that impede/contribute to balanced centricity. Transformative service providers should try to address all actors' psychological needs when co-creating services to achieve network well-being.

Originality/value - This study adopts a novel, multi-actor perspective and thereby presents a conceptual model that contributes to the understanding of balanced centricity. Future research could test this model in other transformative service settings.
\end{abstract}

Keywords Qualitative research, Co-creation, Well-being, Health services, Transformative, Service systems, Transformative service research, Balanced centricity, Network well-being, Psychological needs, Co-creation of services, Tensions/alignments, Multi-actor perspective

Paper type Research paper

\section{Introduction}

Well-being is a central consideration for transformative service research (TSR) scholars and practitioners, especially as it relates to vulnerable populations (Johns and Davey, 2019; Ostrom et al., 2015). Vulnerability refers to actors' inability to fulfill their needs because of a lack of power or control (Virlée et al., 2020). Health-care, as an example of a TSR context highly relevant to societal and individual well-being (LeroiWerelds, 2019), can enhance the well-being of vulnerable patient populations and workers, though such outcomes often are challenging and healthcare systems are in distress (Patrício

The current issue and full text archive of this journal is available on Emerald Insight at: https://www.emerald.com/insight/0887-6045.htm

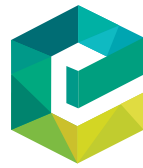

Journal of Services Marketing

35/9 (2021) 1-14

Emerald Publishing Limited [ISSN 0887-6045]

[DOI 10.1108/JSM-11-2020-0466] et al., 2018). As Verleye et al. (2017, p. 35) illustrate, imbalances or situations in which "legitimate interests of at least one actor in a complex service network are not secured," have detrimental effects on patients' well-being and stability of

(C) Fabian Groven, Gaby Odekerken-Schröder, Sandra Zwakhalen and Jan Hamers. Published by Emerald Publishing Limited. This article is published under the Creative Commons Attribution (CC BY 4.0) licence. Anyone may reproduce, distribute, translate and create derivative works of this article (for both commercial and non-commercial purposes), subject to full attribution to the original publication and authors. The full terms of this licence may be seen at http://creativecommons.org/licences/by/4.0/legalcode

The authors gratefully acknowledge the support of the managers from the participating health care institutions as well as the study's participants for their willingness to share their personal experiences.

Funding: This study is funded by Arion Holding B.V.; a Dutch company active in the international health care segment.

Received 20 November 2020

Revised 26 February 2021

Accepted 15 April 2021 
healthcare systems overall. Imbalances can arise from unintended consequences of well-intentioned health-care developments. For example, the focus on productivity in health care encourages health-care staff to serve as many patients as possible, at the expense of patients' need to build trusted relationships with the staff (Berry et al., 2020). Imbalances also might affect other involved actors such as family members (Suárez-Álvarez et al., 2020).

Within service industries such as health care, actors make up multi-actor networks in which their interactions affect other actors' individual well-being and the collective actor-network well-being (Anderson et al., 2018; Taiminen et al., 2020). The current study adopts Leo et al.'s (2019, p. 782) definition of service system well-being to define actor-network well-being as "the aggregate perception of actor assessments of the system in terms of the fulfillment of their collective and by implication, the satisfaction of their individual needs." Balanced centricity, a concept introduced by Gummesson (2007), emphasizes the importance of satisfying all actors' needs. The current study describes a situation in which all network actors' interests and needs are fulfilled simultaneously as "balanced centricity" (Quero and Ventura, 2015; Verleye et al., 2017).

Actors' interactions that affect individual actor and collective actor-network well-being are part of the co-creation of services. With the term "co-creation of services," we refer specifically to the integration of resources in collaborative activities by frontline service employees (FLEs) (e.g. nurses) and focal actors (e.g. patients), influenced by transformative service mediators (TSMs; e.g. family members), that can result in beneficial outcomes and increase actor well-being (Oertzen et al., 2018). TSMs are actors who are involved in the cocreation of services as mediators to support vulnerable focal actors, especially focal actors who are too incapacitated to co-create by themselves (e.g. anxious patients who are not confident enough to question and address health-care staff's decisions) (Johns and Davey, 2019). According to Grönroos and Voima (2013), actor well-being improves when the actor is better off as a result of co-creation of services, whether with respect to the quality of life, health, happiness or some other measure (McColl-Kennedy et al., 2012). Such a view of actor well-being is subjective, such that each actor's evaluation is based on her or his personal experiences (Falter and Hadwich, 2020).

We acknowledge the value co-creation logics' reasoning (Grönroos and Voima, 2013; Vargo and Lusch, 2004), in which (transformative) value and well-being are inherently intertwined (Dean and Indrianti, 2020) and value is "the change in the well-being of a particular actor" (Vargo and Lusch, 2018, p. 740). Co-creation of services affects the wellbeing of all interrelated actors, so one actor's activities in cocreation of services affect not only his or her individual wellbeing but also the well-being of other actors related to him or her (Sweeney et al., 2015). When co-creation of services fulfills all actors' interests and needs (i.e. balanced centricity exists) and, therefore, creates beneficial outcomes for all actors involved, all actors' well-being increases, as well as the multiactor network well-being.

Therefore, we propose that balanced centricity offers an indicator of multi-actor network well-being. That is, when all actors' interests and needs are being met and beneficial outcomes are created for all actors, all the actors become better off, which means their individual-level well-being increases. Furthermore, actors perceive the network as able to fulfill their needs, so multi-actor network well-being increases as well, along with individual actors' well-being (Leo et al., 2019).

However, co-creation of services can result in counterproductive outcomes if tensions exist among the varied interests and needs of different actors (Hillebrand et al., 2015; Oertzen et al., 2018). If the actors' interests and needs are contradictory, the co-creation of services could contribute to the individual well-being of one actor while degrading other, interrelated actors' well-being (Dean and Indrianti, 2020; Plé and Cáceres, 2010). Especially in complex services such as health care, unintended effects on actors' needs could occur (Berry et al., 2020). For example, tension may exist between the need of immobile patients (i.e. focal actors), who cannot bathe independently, to be bathed on a daily basis to maintain their dignity and the need of nurses (i.e. FLEs) to provide this service thoroughly and considerately, such that they cannot provide daily in-bed baths to all patients, given the time constraints involved in their work. Network well-being does not depend solely on a single, recurring activity such as in-bed baths, but it could represent other health-care encounters, and therefore offers a clear illustration of the potential impact of tensions in different actors' needs on the actors' and, ultimately, network well-being.

In the extant literature, the reasons that tensions exist remain unclear. By taking a multi-actor perspective, we seek to explore the origins of both tensions and alignments across the interests and needs of different actors, as well as how they affect network well-being, in accordance with the following research questions:

1 What are actors' (different) interests and needs related to the in-bed bath as a representation of co-created service encounters?

2 From where do tensions and alignments in interests and needs across actors originate?

3 How do tensions and alignments across different actors' interests and needs affect individual actor well-being and how do they affect the achievement of balanced centricity as an indicator of network well-being?

In turn, this study contributes to services marketing literature in three ways. First, it responds to Sweeney et al.'s (2015) call for multi-actor approaches and uses a qualitative, empirical research approach to explore the interests and needs expressed in firsthand health-care experiences described by vulnerable focal actors, FLEs and TSMs. By exploring multiple actors' experiences, we build on research that explores network influences on focal actors' experiences exclusively (Black and Gallan, 2015; Davey and Grönroos, 2019). Second, our empirical study adds to largely conceptual literature on balanced centricity; we introduce a conceptual model that can identify tensions and alignments in interests and needs across actors that impede or contribute to balanced centricity (i.e. satisfaction of all actors' interests and needs). By postulating balanced centricity as an indicator of multi-actor network wellbeing, we establish network well-being as an actionable, less abstract concept in response to calls to examine well-being at the network level, in addition to individual actor well-being 
(Berry et al., 2020). Third, the conceptual model reveals the origin of tensions and alignments across different actors' interests and needs. Previous studies detail what activities health-care actors undertake in the co-creation of services and how these activities might affect (other) actors' well-being (McColl-Kennedy et al., 2012, 2017; Sweeney et al., 2015). By focusing on the origin of actors' interests and needs - or why they take part in the co-creation of services - with respect to network well-being, we provide valuable recommendations for how service managers can address all actors' interests and needs simultaneously and thereby facilitate balanced networks.

\section{Theoretical background}

\section{Balanced centricity and network well-being}

This study addresses the well-being of networks that comprise multiple actors, with the notion that various actors' well-being must be considered in health care (Anderson et al., 2018). To describe multi-actor networks, we turn to definitions of value networks as "service beneficiaries' conceptualizations of actor constellations and their value co-creating/destroying dynamics" (Čaić et al., 2018, p. 180). Our definition of network well-being implies that network well-being depends on the well-being of its individual actors (Leo et al., 2019; Vargo et al., 2017). As noted, individual actor well-being in this study refers to actors' subjective well-being, which is based on actors' experiences.

We anticipate that individual actors' well-being increases if the co-creation of services leaves them better off (Grönroos and Voima, 2013), such that they perceive some improvement, based on their personal experiences (Falter and Hadwich, 2020). Individual actors integrate resources through the co-creation of services, which results in their well-being if it generates beneficial outcomes for them (Grönroos and Voima, 2013; Oertzen et al., 2018; Sharma et al., 2017). An actor's level of well-being depends on both his or her own and others' activities in the co-creation of services (Frow et al., 2016). Particularly for vulnerable focal actors such as impaired patients, well-being is affected by their relationships with FLEs and TSMs (e.g. family-supporting patients in co-creation of services).

Such interrelationships between actors and their respective resources necessitate a holistic view of network well-being, as a complex phenomenon. We propose balanced centricity as an indicator to simplify this complexity (Leo et al., 2019). Gummesson $(2002,2007)$ introduced the concept of balanced centricity as a marketing philosophy that stresses the importance for organizations to meet all actors' interests and needs, instead of adopting only a customer-centric approach. Rather than solely a philosophy, we investigate balanced centricity as a system-level outcome, reached only if all actors' interests and needs are satisfied (Gummesson, 2007, 2008; Quero and Ventura, 2015).

The satisfaction of actors' interests and needs is a beneficial outcome of co-creation of services that increases actors' individual well-being; service co-creation can also increase network well-being, depending on the embedded actors' assessments of the network's capacity to fulfill their needs (Leo et al., 2019). The opposite of balanced centricity is an imbalanced network, which results if co-creation of services generates beneficial outcomes for one actor and counterproductive outcomes for other, interrelated actors
(Reypens et al., 2016). In health-care services, examples of counterproductive outcomes include an excessive burden on FLEs (e.g. due to high focal actors' demands), dissatisfied TSMs (e.g. due to focal actors' criticism) or negative emotions among focal actors such as feelings of dependence or indignity (e.g. due to FLEs' unavailability). Beneficial outcomes must accrue to all actors to remain within a balance threshold and avoid surpassing it, which would diminish overall network wellbeing (Hillebrand et al., 2015; Verleye et al., 2017).

\section{Tensions and alignments in interests and needs across actors}

Interests and needs determine actors' activities in the cocreation of services (Neghina et al., 2017; Osei-Frimpong, 2017). Actors' motives for ensuring their needs define the resource integration process and give direction to co-creation (Findsrud et al., 2018). When interests and needs across actors are asymmetric, the result might be co-destruction and "a decline in at least one of the systems' (e.g. actors) well-being" (Plé and Cáceres, 2010, p. 431).

Extant literature on balanced centricity largely consists of conceptual studies, while empirical studies are largely lacking. Even the few empirical studies of co-creation in networks that take multiple actors' perspectives tend to ignore the tensions and alignments in interests and needs across actors in relation to network (im)balances. Verleye et al. (2017) consider network imbalances from a patient (i.e. focal actor) perspective and conclude that imbalances originate from competing logics (e.g. patient care vs business logics). For example, they observed patients being left unwashed (their basic care needs left unmet) as a result of the health-care organization's focus on efficiency (to meet their business needs). We build on their work by empirically zooming in on the effect of tensions and alignments between the interests and needs of different actors from the perspective of three interrelated actors in a health-care setting, to understand the sources of their interests and needs (Sweeney et al., 2015) and thereby explore whether balanced centricity is attainable.

By empirically exploring tensions and alignments in interests and needs across different health-care actors, we also aim to enhance understanding of the interrelationships between actor and network well-being in a transformative service setting (Osei-Frimpong, 2017). Transformative service settings that feature vulnerable actors generally create a higher risk of tensions among network actors (Rosenbaum, 2015). As a transformative setting, for this study, we address the recurring service encounter of in-bed baths, which usually are dyadic health-care activities that require the direct involvement of vulnerable patients being bathed in bed and nurses providing the in-bed bath. Yet this service co-creation also is influenced by a multi-actor network (Oertzen et al., 2018), such that the setting also includes the patient's family members, who are involved mostly indirectly (i.e. as informal caregivers and TSMs). Still, their interests and needs need to be fulfilled to achieve balanced centricity, in which all actors' interests and needs are satisfied. The in-bed bath is an important daily health-care encounter that is representative of other health-care encounters in which tensions and alignments between actors come to the surface. 


\section{Methodology}

\section{Setting and approach}

Health care is an appropriate setting to explore the effect of tensions and alignments across actors' interests and needs on multi-actor network well-being, due to its high level of complexity and the presence of many actors, actions and interactions (Pinho et al., 2014), even within single health-care encounters. Furthermore, health-care is a typical transformative service that has a significant impact on vulnerable actors with physical and/or cognitive impairment. We investigate in-bed baths because they represent transformative health-care encounters that affect the well-being of multiple actors, including vulnerable focal actors, with potentially competing interests. Bedridden patients (i.e. the focal actors) who cannot bathe independently feel embarrassed and worried about their dignity (Downey and Lloyd, 2008) and the in-bed baths, as recurring service encounters, can have significant impacts on their quality of life and well-being (Ahluwalia et al., 2010). Nurses and families may be affected by this service encounter in different ways. Nurses (i.e. FLEs) perceive in-bed bathing as a relatively straightforward, daily routine, with little impact on their personal well-being (Kitson et al., 2013). Patients' family members (i.e. TSMs) likely view such personal hygiene encounters as determinants of the quality of care provided to their loved ones. These different actor perceptions could hint at differences in actors' interests and needs with regard to in-bed baths, as also might exist in other daily health-care encounters such as feeding, dressing and toilet assistance.

The data collection took place in nursing homes in a Western European country. Descriptions of in-bed bathing experiences were collected inductively from three actor groups within this setting: patients, nurses and patients' family members. Their experiences reflect various bathing methods across four nursing homes from which we gathered data. In one, patients are bathed exclusively in bed with water and soap (i.e. traditional in-bed bath), but three nursing homes also use a washingwithout-water concept, relying on disposable, prepacked bathing systems. The nursing homes were affiliated with different institutions, but they provided care to patients with comparable physical and cognitive impairments.

With a qualitative approach, we inductively explored the actors' service experiences to gain deep, holistic insights into the network and its complex web of actor interdependencies (Gummesson, 2005). We sought actors' personal interpretations of the in-bed bath because co-creation is experience-centric (Oertzen et al., 2018). Therefore, we adopted an interpretive, phenomenological stance to explore the meanings that different actors ascribe to their experiences with in-bed baths (Rynes and Gephart, 2004).

\section{Data collection}

We collected experiences from different actors to draw conclusions about multi-actor networks, as the unit of analysis. The units of observation were individual patients (focal actors), nurses (FLEs) and family members (TSMs) within networks. The patients we interviewed expressed minimal cognitive impairments but moderate to high physical impairments. Managers of the participating nursing homes selected eight patients on their (cognitive) ability to share their in-bed bath experiences; all agreed to participate. The aim was to interview at least one nurse and one family member for each patient included. However, for some patients, family members were not available. For each patient, at least one nurse was interviewed who had bathed him or her and for five patients, we also interviewed a family member. Thus, in total, we conducted 19 in-depth interviews with eight patients, six nurses and five family members (Table 1), resulting in five triads and three patient-nurse dyads (Figure 1) that are part of multi-actor networks. We included data from the patient-nurse dyads because they provide direct information about patients' and nurses' experiences, as well as indirect information about the family's experiences. By interviewing health-care actors directly related to one another, we also achieved data triangulation and increased the validity and reliability of the findings (Pandit, 1996). No new information emerged from the final interviews, so we perceived that data saturation had been achieved (Saunders et al., 2018).

The interview scripts varied for the interviews with patients, nurses and family, in which we inductively (i.e. without theoretical preconceptions) collected actors' general experiences with, as well as their interests and needs related to, the in-bed bath (see the Appendix). Open questions helped encourage the interviewees to elaborate on their experiences in their own words, without imposing the researchers' ideas (Gioia et al., 2012). Furthermore, follow-up questions sought to identify possible socially desirable answers. The first author transcribed all interviews verbatim within a week; none of the interviews was coded or analyzed before all the other interviews had been conducted.

\section{Data analysis}

The data analysis process shown in Figure 2 consisted of several inductive steps at the start and deductive steps at the end of the process that allowed the codes to evolve across data and theory. The first author read the interview transcripts several times to become familiar with the data (254 single-spaced pages). Then, this same author performed open coding of the data in NVivo1 1 and all authors discussed a sample of the data during an open-coding meeting. Among the 75 first-order codes obtained, $80 \%$ were mentioned in at least two interviews, indicating inductive thematic saturation (Saunders et al., 2018). The first author grouped these first-order codes in an iterative process, on the basis of theory and discussions with the wider research team. This represents the only abductive step in the process, to establish "a dialogue between theory and empirical material" (Alvesson and Kärreman, 2007, p. 1270). One of the discussions with the research team resulted in the identification of a suitable theoretical framework (i.e. self-determination theory [SDT], as we present subsequently). This theoretical framework marked a shift from induction to deduction in the data analysis process; the subsequent steps used this theoretical framework to group the first-order codes into second-order categories, which were based on the theoretical framework. That is, some of the data analysis steps are inspired by abductive methodologies (Gioia et al., 2012), but rather than being purely abductive, our process combines inductive steps with several deductive steps, with one abductive step in the middle (Figure 2). 


\begin{tabular}{|c|c|c|c|c|c|c|}
\hline Actor & $\begin{array}{l}\text { Nursing } \\
\text { home }\end{array}$ & Gender & Age & Educational level & Bathing method(s) & $\begin{array}{l}\text { Interview length } \\
\text { in minutes }\end{array}$ \\
\hline \multicolumn{7}{|l|}{ Actor network 1} \\
\hline Patient 1 (Mrs Smith) & 1 & Female & 95 & Primary school & Water and soap & 66 \\
\hline Nurse 1 (James) & & Male & 28 & Intermediate nursing & & 55 \\
\hline Family 1 (son Walter) & & Male & 67 & University & & 42 \\
\hline \multicolumn{7}{|l|}{ Actor network 2} \\
\hline Patient 2 (Mrs Green) & 1 & Female & 81 & Primary school & Water and soap & 45 \\
\hline Nurse 1 (James) & & Male & 28 & Intermediate nursing & & 55 \\
\hline \multicolumn{7}{|l|}{ Actor network 3} \\
\hline Patient 3 (Mrs Brown) & 1 & Female & 87 & Primary school & Water and soap & 57 \\
\hline Nurse 2 (Fred) & & Male & 40 & Intermediate nursing & & 48 \\
\hline Family 3 (daughter Bessie) & & Female & 60 & Primary school & & 52 \\
\hline \multicolumn{7}{|l|}{ Actor network 4} \\
\hline Patient 4 (Mrs Wilson) & 1 & Female & 92 & Primary school & Water and soap & 35 \\
\hline Nurse 2 (Fred) & & Male & 40 & Intermediate nursing & & 48 \\
\hline Family 4 (son Edward) & & Male & 63 & University & & 33 \\
\hline \multicolumn{7}{|l|}{ Actor network 5} \\
\hline Patient 5 (Mr Taylor) & 2 & Male & 80 & Secondary school & Water and soap and & 57 \\
\hline Nurse 5 (Kim) & & Female & 23 & Advanced nursing & washing without water & 51 \\
\hline \multicolumn{7}{|l|}{ Actor network 6} \\
\hline Patient 6 (Mr Thomas) & 3 & Male & 60 & Intermediate & Water and soap and & 41 \\
\hline Nurse 6 (Florence) & & Female & 52 & Intermediate nursing & washing without water & 48 \\
\hline Family 6 (relative Minnie) & & Female & 56 & Applied university & & 30 \\
\hline \multicolumn{7}{|l|}{ Actor network 7} \\
\hline Patient 7 (Mrs Harris) & 3 & Female & 72 & Secondary school & Water and soap and & 42 \\
\hline Nurse 7 (Alice) & & Female & 32 & Intermediate nursing & washing without water & 40 \\
\hline Family 7 (husband Frank) & & Male & 73 & Applied university & & 30 \\
\hline \multicolumn{7}{|l|}{ Actor network 8} \\
\hline Patient 8 (Mr Robinson) & 4 & Male & 72 & Intermediate & Water and soap and & 32 \\
\hline Nurse 8 (Polly) & & Female & 46 & Intermediate nursing & washing without water & 47 \\
\hline
\end{tabular}

To facilitate coding by independent researchers using the identified second-order categories, the first author unitized the data samples (Campbell et al., 2013). After coding two data samples, the researchers discussed their findings, which aided in the interpretation of the data. Next, the first author coded the rest of the data. Although the point of true saturation cannot be determined, most first-order codes could be grouped in one of the second-order categories, which suggests a priori thematic saturation (Saunders et al., 2018). Finally, the first author integrated these data by mapping relationships among the second-order categories (Spiggle, 1994) and discussed the findings with the whole research team.

\section{Findings}

Actors' interests and needs

The analysis of the data uncovered several actor interests and needs. So far, we have used the terms "interests" and "needs" interchangeably; in the presentation of the results, we simplify the wording and refer to needs, which encompass both forms.
Needs of the focal actor

First, patients (i.e. the focal actors) seek control over their bathing, which became apparent in their descriptions of experiences in which they lacked such control, such that when "you get that nurse and then you get that nurse, I don't complain. There is not anything I can choose anyways" (Mrs Green). Second, patients need to gain a sense of selfconfidence from performing some elements of bathing by themselves, as signaled by both positive and negative reports such as the assertions "I enjoy that I can still wash parts of my body myself" (Mr Taylor) or "If I lie in bed, I often think "I wish I could bathe myself." Now I cannot do anything anymore" (Mrs Brown). Third, patients expressed their need for normality after a bath (e.g. undertaking activities similar to those performed by healthy persons): "For myself and for others I think it is good to be bathed. So I feel capable to be normal again" (Mr Taylor). As a negative example, one patient noted a lack of normality: "Actually, a person should feel fit after an in-bed bath. Unfortunately, I don't have that luck, probably because of the condition of my lungs" (Mr Thomas). Fourth, patients cited their need for safety, emotionally and 
Figure 1 Multi-actor networks
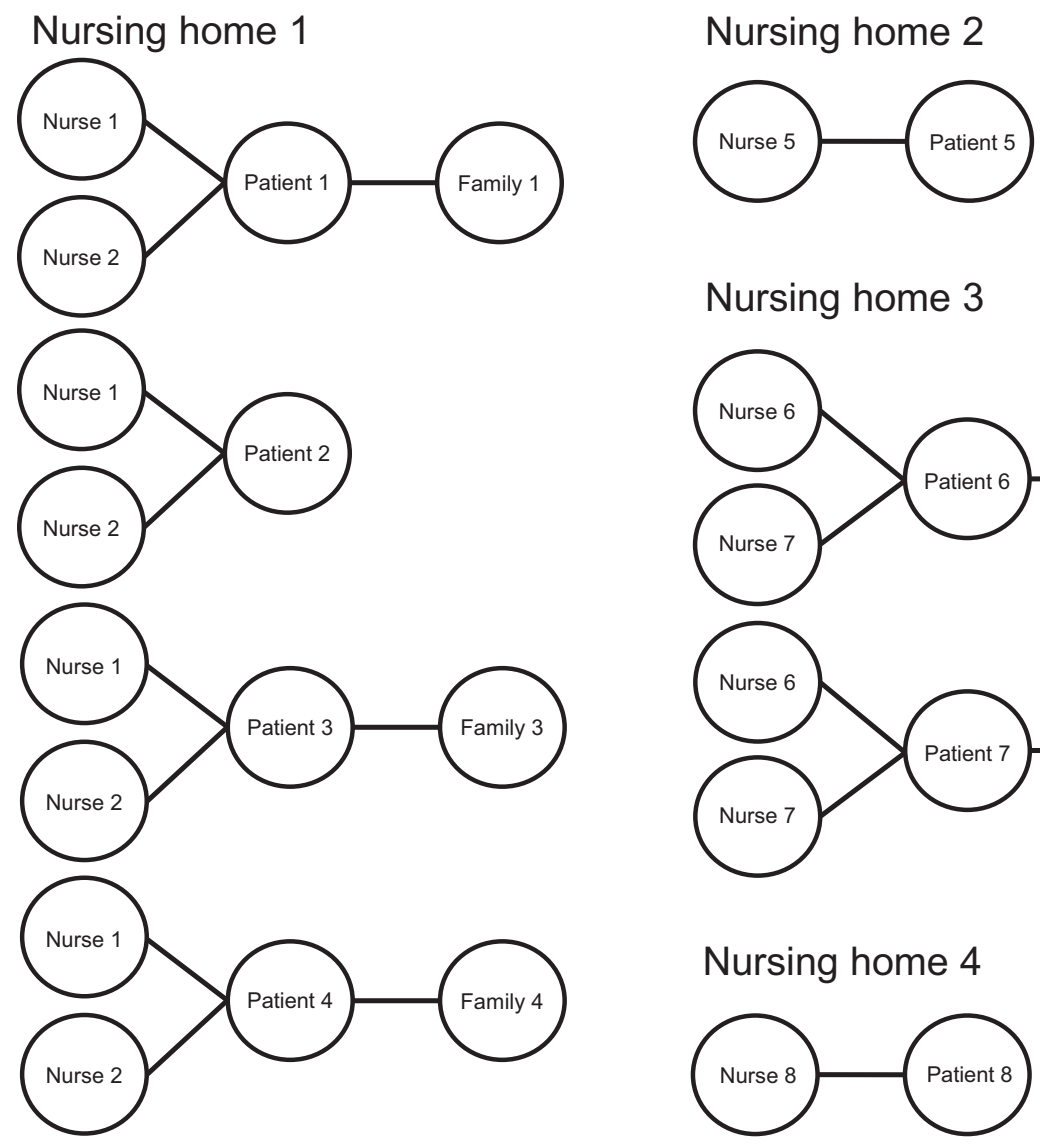

Nursing home 3

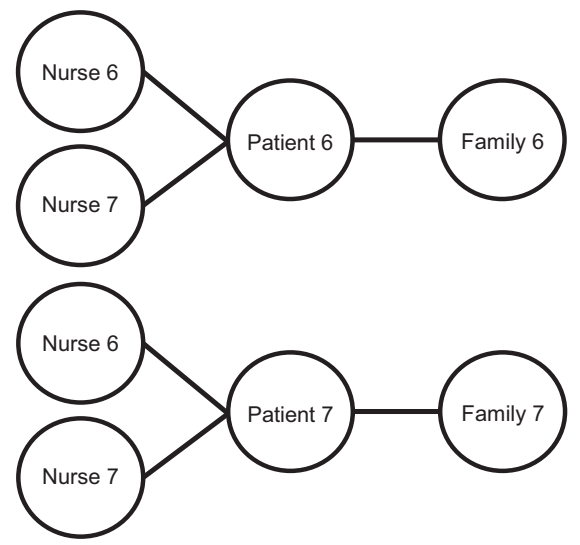

Nursing home 4

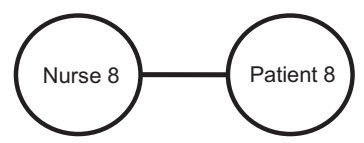

physically, in their direct and intimate interactions with nurses during the in-bed baths such as a patient who explained, "Most of the time, I am bathed by two nurses. Because they have to turn me around and then they have to firmly hold me because I am terrified that I will fall out of bed" (Mrs Green). Fifth, patients indicate a need for pleasant relationships with nurses: "I would have preferences for certain nurses because of the way they treat me" (Mr Thomas).

\section{Frontline service employees' needs}

The first need among nurses (i.e. FLEs) is to act according to their personal preferences (i.e. as human beings, not as nurses): "Personally, I like to primp women" (Nurse Polly). Yet the nurses also noted the necessity to put their personal preferences aside sometimes to meet patients' or families' requests, which limited their ability to organize the in-bed bath encounter as they preferred. Second, nurses also expressed their need for professionalism, in describing situations that identified them as skilled professionals able to achieve nursing goals (e.g. patient satisfaction): "But I also must take care of patients that I cannot really get along with. In those cases, I have to put my thoughts aside and simply make the best of it. And afterward, if everything went well I think to myself, 'Oh, well, fine, if he is satisfied then I am as well'" (Nurse Kim). On some occasions, however, nurses worry about doing their job professionally, often due to contextual factors such as staff shortages: "You see, last weekend, one colleague could not come to work and then it is only the three of us working at this ward. In those cases, I can get annoyed because I know, 'Oh, I still need to take care of that many people"' (Nurse Polly).

Third, similar to patients, nurses expressed a need for safety. If patients and nurses get along well, nurses feel emotionally comfortable, but other encounters cause them emotional discomfort (e.g. patients actively asking nurses to bathe intimate body parts). Fourth, nurses also acknowledge their need for pleasant relationships, as indicated by their descriptions of their relationships with patients: "I like that you can see that they appreciate what I'm doing and that they show interest in my personal life, even though they are patients living in the nursing home. If they would not ask personal things, I would feel less satisfied because then you only pay attention to them and they do not care about me" (Nurse Alice).

\section{Transformative service mediators' needs}

In contrast with patients and nurses, family members (i.e. TSMs) generally are not physically present during the in-bed bath. Many family members interviewed for this study indicated that they were not even aware of how their loved one is bathed. Still, two needs emerged. First, these informants indicated their need for self-assurance; they want to feel confident about their abilities as informal caregivers. Family members who believed the patients were being properly cared 
Figure 2 Data analysis process

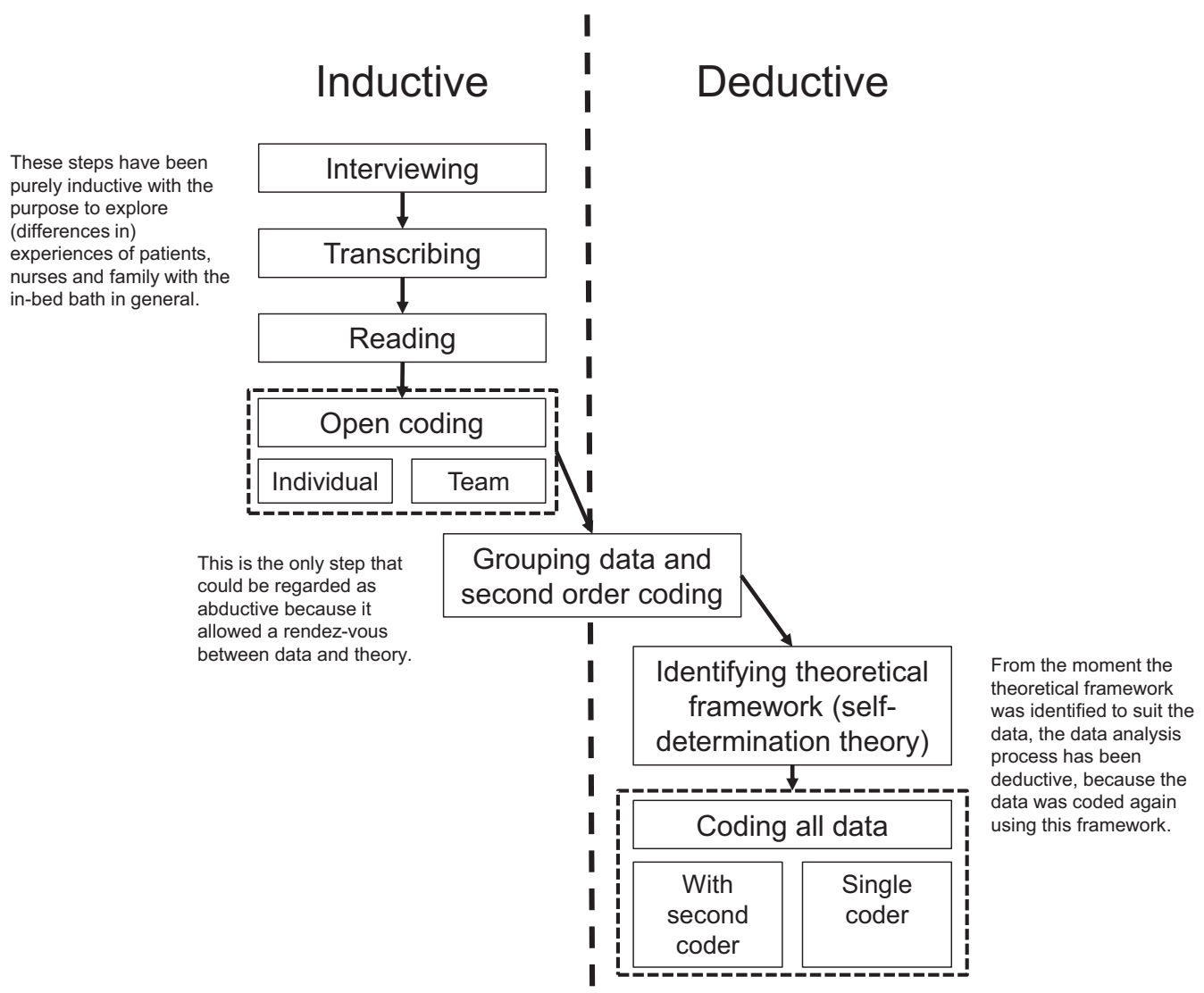

for in the nursing home also felt assured that they were living up to their responsibility to protect patients' well-being. Others felt guilt though, due to their concerns about insufficient care provision: "It makes me happy that I can see that they take care of her hair and her nails. That makes me happy, then I think, 'Thank God.' Imagine, she would neglect herself and she would say 'I don't need to have my hair done.' That would hurt. Then I would think, 'Oh no, I put her somewhere where she does not want to be.' I wouldn't like that, not for her and not for myself" (daughter Bessie).

Second, this study identified family members' need for relational maintenance through ties with both patients and nurses. One family member indicated both the importance of such good relationships and the challenge of maintaining them with nurses and the patient simultaneously because the patient was dissatisfied with her care: "You see, I want to protect my mother but also the nurses. I feel stuck in between my mother and the nurses, which can be very difficult sometimes" (daughter Bessie).

Psychological needs as a lens to group actors' needs

During the data analysis process, the author team engaged in several rounds of discussion and realized that the actors' needs presented so far closely matched the basic psychological needs of autonomy, competence and relatedness, which are central to SDT. SDT is a motivational theory that highlights the importance of psychological needs as determinants of optimal well-being in daily life (Ryan and Deci, 2000). Autonomy, competence and relatedness are innate and universal needs and, therefore, are considered higher-order needs that explain the origins of actors' lower-order interests and needs. In other words, we regard lower-order needs as actor-specific manifestations of basic psychological needs. Autonomy implies a need to experience control and self-organize experiences and behaviors (Deci and Ryan, 2000; Sharma et al., 2017). In our study, autonomy is reflected in focal actors' lower-order need for control (e.g. having a say in which nurse provides the in-bed bath) and FLEs' lower-order need to meet their personal preferences (e.g. primping patients). Competence refers to an experience of proficiency in performing tasks in physical and social contexts (Deci and Ryan, 2000; Sharma et al., 2017), as represented by focal actors' lower-order needs for selfconfidence and normality (i.e. to be proficient in their daily lives), FLEs' lower-order need for professionalism (i.e. to be proficient as a nurse) and TSMs' lower-order need for selfassurance (i.e. to be proficient as an informal caregiver). Finally, relatedness implies a desire for safe, intimate relationships and a sense of belonging (Baumeister and Leary, 1995; Sharma et al., 2017), which is reflected in focal actors' and FLEs' lower-order needs for safety and pleasant relationships and TSMs' lower-order need for relational maintenance. Fulfillment of these needs contributes to individual actor well-being (Engström and Elg, 2015; Kasser and Ryan, 1999). In other words, activities and relationships that fulfill the needs of autonomy, competence and relatedness contribute to well-being, whereas ill-being results from the lack of satisfaction of these needs (Ryan and Deci, 2000). In this 
study, ill-being represents a deprivation of actors' mental wellbeing (e.g. patients experiencing anxiety or low levels of vitality, nurses experiencing low job satisfaction), caused by actors' experiences with the in-bed bath that negatively affect the fulfillment of their psychological needs.

\section{Effect of tensions and alignments in actors' psychological needs on network well-being}

Actors try to fulfill their needs through the co-creation of services (Oertzen et al., 2018). If tensions exist among actors' psychological needs, not all actors' lower-order needs, related to their psychological needs, are being fulfilled simultaneously in the co-creation of services. By contrast, alignments imply the fulfillment of multiple actors' needs at once.

By accounting for interrelationships among actors, we move from the actor to the network level. Our study data provide rich, illustrative evidence of how co-creation of services (which actors initiate to fulfill their own psychological needs) affects the need fulfillment of other actors, and thus determines balanced centricity. Because most illustrative evidence refers to interrelationships among focal actors and FLEs, we focus on these dyads in this section. However, tensions and alignments between TSMs on the one hand and focal actors and FLEs on the other hand also emerge.

Tensions and alignments: focal actors' needs and network well-being

Patients' (i.e. focal actors') choice to participate in the in-bed bath or not, to fulfill their autonomy- or competence-based needs, can affect nurses' (i.e. FLEs') need for autonomy. Nurse Polly explained how a patient's unwillingness to bathe parts of his body himself impedes her need fulfillment: "If I ask him if I need to wash some parts of his body, he simply tells me to do that. But he is able to wash those parts himself. That really bothers me." Her personal preference that the patient washes parts of his body himself is overruled by the request of this focal actor and his unwillingness to participate. Patients' participation also enhances nurses' competence-based need for professionalism. That is, nurses' need for competence can be fulfilled when their work is facilitated by patients who assist during the bath: "For some patients, I need only $20 \mathrm{~min}$ to give an in-bed bath, whereas others might take an hour, for example. If I have to bathe patients who can participate, I'm finished earlier and I can easily bathe eight patients a day" (Nurse Florence).

Other illustrative evidence relates to patients who share information with nurses to fulfill their own autonomy-based need for control, a step that can make nurses feel empowered to provide a proper bath, which then fulfills their need for competence such as when patients offer insights into their preferences: "I think most patients want to look neat and cared for, but many cannot take care of that themselves and then we need to do it. Sometimes patients share their preferences and otherwise, the family does" (Nurse Alice). However, if patients' preferences deviate too much from nurses' routines and standards, it is difficult for nurses to meet them in a professional way. For example, Nurse Florence explained the difficulty of meeting patient preferences with respect to timing: "Bathing at the request of the patient could be possible but would have major consequences. We would not have enough personnel in the afternoon to bathe people, so we then would need to reorganize our whole process" (Nurse Florence).

Apart from sharing information, patients interact with nurses to invest in their relationships and thereby fulfill their need for relatedness, which also affects nurses' need fulfillment. Pleasant interactions with patients can ease care provision and fulfill nurses' need for competence: "It is more pleasant to do my job and also for the person who I am taking care of. It is more convenient if they like to see me. It seems to be easier as well" (Nurse Polly). If instead patients display negative moods in their interactions, it becomes more difficult for nurses to do their jobs professionally: "If the patient is in a bad mood, the care provision process runs less pleasantly because if he is angry, he can reject care by asking us to leave him alone. That is tough because it then takes longer to take care of him" (Nurse Florence).

Finally, patient interactions influence nurses' need for relatedness. Nurse Polly explains the positive outcomes when patients show appreciation for their efforts: "If patients appreciate what you are doing for them, that they are taken care of, you also get a better relationship with them."

Tensions and alignments: frontline service employees' needs and network well-being

Several pieces of illustrative evidence indicate positive or negative impacts of nurses' (i.e. FLEs') adherence to nursing routines and policies, to fulfill their own competence-based need for professionalism, on patients' (i.e. focal actors') needs. For example, nurses provide patient-centered care, which requires accounting for the patients' preferences and accepting their directions, which, in turn, makes the nurses feel professional. Such efforts can have a positive impact on patients' need for autonomy, as noted by one patient: “I frequently had wounds on my groin. As they bathe me with clean water and Sunlight soap, it healed. I insisted on the use of that" (Mrs Smith). Nursing policies also often prescribe the encouragement of patient participation in the care process. Such encouragement can have a positive impact on patients' competence-based need for self-confidence. For example, Nurse Kim described encouraging a patient to wash at least partially: "No, generally, he helps where he can during the inbed bath. You just give him a washing mitt and then you pay attention to what he can do himself and I take over the rest." However, nurses sometimes follow nursing routines and policies that make them feel competent but impede the fulfillment of patients' autonomy-based need for control: "We live up to patients' requests unless this is not possible due to agreements with doctors or the family" (Nurse Alice). Here, Nurse Alice allows agreements made with doctors or the family to prevail over patient preferences to satisfy her interest in professionalism. The time at which nurses give in-bed baths also often depends on nursing routines, rather than patients' preferences, which could affect patients' ability to engage in other activities: "I cannot always go to the physiotherapist. Because sometimes they bathe me too late and I cannot make it" (Mrs Smith). Mrs Smith cannot undertake other activities, as any "normal" person can, which impedes the fulfillment of her competence-based need for normality.

In addition to following nursing routines and policies, nurses seek information, mainly to fulfill their own competence-based 
need for professionalism, which influences the fulfillment of patients' autonomy-based need for control, particularly if nurses actively seek information about patients' preferences: "Yes, we also bathe some patients with water and soap. We ask our patients if they want to be bathed with washing without water or with water and soap" (Nurse Florence).

Finally, nurses generally interact with patients to satisfy their own needs for relatedness or competence, which can also improve patients' need fulfillment. With regard to patients' relatedness-based need for pleasant relationships, we identify a positive effect in a quote from one of the nurses, explaining efforts to enter into one-on-one interactions with patients to provide personal attention, as part of professional care: "Usually, I bathe patients all by myself. Most patients don't feel comfortable being bathed by two nurses because then the nurses have a talk with each other and don't involve the patient in the conversation" (Nurse James). This illustrative evidence also implies a potential negative effect of a lack of personal attention; the patient might miss a sense of having a pleasant relationship if bathed by two nurses and excluded from their interactions. One patient confirmed the importance of personal contact in terms of a need for relatedness: "Yes, it is nice to get attention from the nurses, then you feel at home" (Mrs Smith).

Tensions and alignments: transformative service mediators' needs and network well-being

Available data on family members (i.e. TSMs') interdependencies with patients (i.e. focal actors) and nurses (i.e. FLEs) illustrate some notable actor experiences. For example, in the patient-family dyad, illustrative evidence shows a positive effect of family members' activities (to fulfill their own competence-based need for self-assurance) such as organizing patients' clothes, on patients' autonomy-based need for control: "I tell the nurses 'In the closet, you can find my clothes.' My daughter makes sure the right clothes are prepared. My daughter says, 'Mother, I hung up your clothes here so they can put you in these"' (Mrs Brown). Conversely, family members' personal interactions with the patient (which might be executed to fulfill their own relatedness-based need for relational maintenance) can negatively affect patients' autonomy-based need for control. One family member persuaded a patient, her mother, to accept being bathed by a male nurse: "My mother had struggles being bathed by a male nurse in the beginning. I told my mother, 'Listen, mother, it is normal to be bathed by a man.' Now she takes it for granted" (daughter Bessie). In this case, the patient's preference for female nurses was ignored by her daughter, who persuaded the patient to accept male nurses. The daughter did so to avoid unpleasant in-bed bath encounters for male nurses, in that the patient otherwise would have resisted the bath.

In the opposite direction, the fulfillment of a family member's competence-based need for self-assurance can be influenced by the information shared by patients, often in the form of complaints. Patients complain to fulfill their own autonomy-based need for control, in an effort to trigger other actors to undertake action to improve the patients' care experiences. At the same time, patients' complaints can make family members feel less competent as informal caregivers: "I would find it terrible if my mother would tell me that she did not get a shower for over two weeks" (daughter Bessie).
Interdependencies also arise between family members and nurses. For example, family members who share information with nurses (to fulfill their competence-based need for selfassurance) can affect nurses' competence-based need for professionalism, which tends to be positive if the information helps the nurse provide better care: "Sometimes, the family tells us that the patient smells. Family can detect that easier than us because we are constantly working at the ward, and therefore don't always notice smells" (Nurse James). This information helps nurses provide services to help the patient smell nice again. Conversely, family members sometimes share information through complaints, which might negatively affect nurses' need for competence: "Personally, I think it is very important that family members are satisfied as well [with the inbed bath]. Otherwise, they will complain. That would make me think I am not doing my job well" (Nurse Kim).

Nurses' activities in the co-creation of services, in turn, can influence family members' competence-based need for selfassurance, as illustrated in the following quote: "I heard many times that patients sometimes don't want to be bathed but that the family demands us to give an in-bed bath. 'Just give her something that will relax her like a tranquilizer so you can bathe her.' We are helpless in such cases. That is not allowed" (Nurse Kim). Nurses observe nursing policies to fulfill their own competence-based need for professionalism, so they cannot tranquilize patients to bathe them. Subsequently, the patient is not bathed, which may leave the family feeling less competent because they failed to assure what the family perceives to be proper care. As a positive effect, nurses who actively ask family members for information (to fulfill their own competencebased need for professionalism) offer these actors a means to protect patients' well-being and fulfill their need for competence: "We organize meetings with family to discuss problems and come up with solutions together" (Nurse Fred).

\section{Discussion}

\section{Theoretical contributions}

Health-care services can enhance the well-being of vulnerable patient populations and other health-care actors (Ostrom et al., 2015). However, the involvement of many actors, each with their own interests, makes health care highly complex (Pinho et al., 2014), which influences actor and network well-being. Therefore, this study explores actors' experiences from a novel multi-actor perspective. Drawing on multiple actors' experiences, this study proposes balanced centricity (Gummesson, 2007) as an indicator of network well-being. To assess balanced centricity, we focus on the multi-actor service setting of in-bed baths - a recurring, co-created service encounter related to basic care - which was associated with an imbalance identified in prior research (Verleye et al., 2017). The results we derived from our in-depth interviews with focal actors (i.e. patients), FLEs (i.e. nurses) and TSMs (i.e. family members) suggest the conceptual model in Figure 3, which depicts the influence of tensions and alignments in psychological needs across actors on balanced centricity through co-creation of services. The conceptual model addresses our research questions.

The first and second research questions center on actors' interests and needs in co-created service encounters. In 
Figure 3 Conceptual model

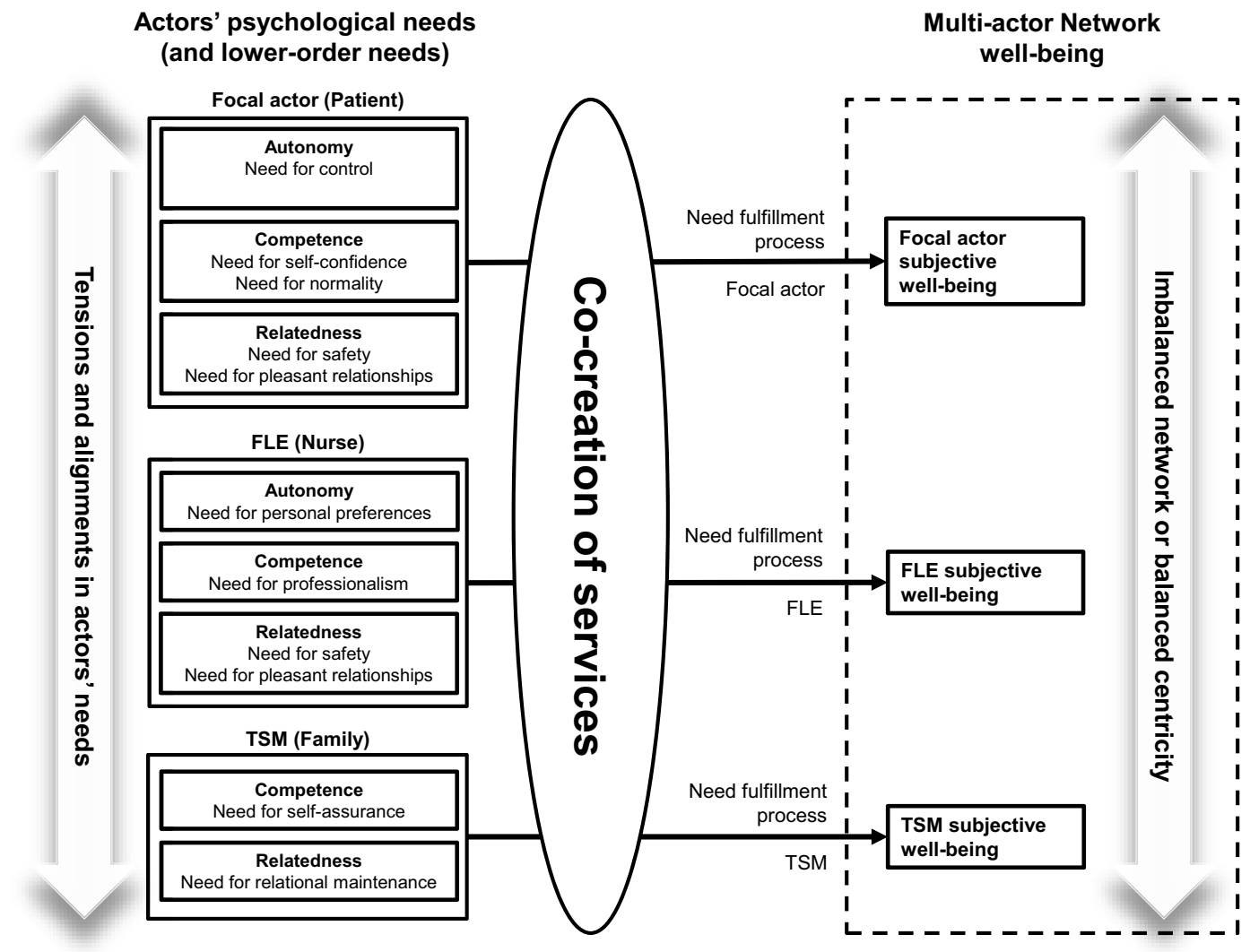

response to the first research question, our empirical, multiactor research approach reveals that the interests and needs of all three actors differ. Focal actors need control, selfconfidence, normality, safety and pleasant relationships; FLEs express needs for personal preferences, professionalism, safety and pleasant relationships; and TSMs mainly indicate needs for self-assurance and relational maintenance. Although actors' interests and needs differ, SDT emerges as instrumental for classifying these interests and needs according to higher-order psychological needs of autonomy, competence and relatedness (Deci and Ryan, 2000). This finding addresses our second research question, which pertains to the origin of tensions and alignments between interests and needs of different actors. That is, universal, often unconscious, psychological needs are higher-order needs that give rise to actor-specific, more conscious, lower-order needs.

As a motivational theory, SDT suggests that the basic psychological needs of autonomy, competence and relatedness explain actors' goal pursuit and that people are intrinsically motivated to perform activities that they believe will contribute to these innate psychological needs (Deci and Ryan, 2000; Engström and Elg, 2015). In our conceptual model, actors express different interests and needs (e.g. patients' need for selfconfidence) that stem from their psychological needs (e.g. competence), which they try to satisfy through co-creation of services (e.g. patients execute parts of the in-bed bath themselves). When actors can fulfill their interests and needs by co-creating services, it satisfies their higher-order psychological needs, resulting in their increased well-being. Prior studies similarly predict the achievement of actor well-being through the realization of basic and higher needs (Falter and Hadwich, 2020), which the current study extends by exploring multiple actors' needs simultaneously. Furthermore, we answer Osei-Frimpong's (2017) call for research that takes an SDT perspective to assess multiple actors' motivations to co-create and determine how consequent actor behaviors affect other actors.

Our third research question pertains to how tensions and alignments between interests and needs across actors affect actors' well-being and the achievement of balanced centricity, as an indicator of multi-actor network well-being. Our results show that actors aim to fulfill their needs through the cocreation of services, which affects the fulfillment of other actors' needs as well, whether positively or negatively, with relevant implications for these other actors' well-being, as well as network well-being. In the conceptual model in Figure 3, balanced centricity is enhanced if all actors' psychological needs are satisfied such as when the lower-order interests and needs of all actors are aligned, enabling all actors' interests and needs to be fulfilled simultaneously through the co-creation of services. If tensions arise between the interests and needs of different actors though, not all actors' psychological needs can be satisfied, which impedes balanced centricity and ultimately network well-being. The vertical two-pointed arrow on the left in our conceptual model reflects these tensions and alignments between actors' needs; the similar arrow on the right depicts the effect of these tensions and alignments on network well-being. 
To increase network well-being, the psychological need fulfillment of all actors is important, not only for those directly involved in the co-creation of services (i.e. patients and nurses) but also for other actors such as TSMs, who support vulnerable focal actors in the co-creation process (i.e. family members) (Johns and Davey, 2019). If tensions between TSMs and other actors' interests and needs exist, network well-being could be threatened by TSMs' activities in the co-creation of services that impede the fulfillment of other actors' psychological needs. For example, family members' complaints (which they raise to ensure proper care provided to the patient and to satisfy their own competence-based need for self-assurance) can negatively affect nurses' need for competence (i.e. nurses feel they did not do a good job).

In particular, psychological need fulfillment should increase network well-being in a transformative setting such as health care. However, because well-being is generally described as multidimensional (Falter and Hadwich, 2020), optimal wellbeing can be realized only if all possible actors' needs are fulfilled. Yet, as the current study demonstrates, psychological needs are vital for network well-being in a TSR setting, featuring vulnerable focal actors who depend on other actors such as patients depending on nurses and family. In this sense, our study contributes to TSR and its efforts to increase vulnerable focal actors' well-being (Johns and Davey, 2019). Furthermore, we contribute to the literature on well-being by exploring both individual actor well-being and well-being at a network level (Berry et al., 2020).

In response to the need for multi-actor perspectives, this study of multi-actor networks also extends the research on balanced centricity by empirically establishing crucial roles of both tensions and alignments across the needs of different actors (McColl-Kennedy et al., 2012; Ng et al., 2016; Sweeney et al., 2015). By showing that balanced centricity is an indicator of network well-being, this study advances discussions of network well-being to a more concrete, actionable level. The empirical results refer to in-bed baths, which represent a specific, crucial and recurring co-created service encounter in health-care services. We predict that the findings are relevant to other transformative service encounters as well, especially in health care such as feeding patients or medical checkups.

\section{Managerial implications}

$\mathrm{Ng}$ et al. (2016) identify different styles that service providers can adopt to support co-creation; this study specifies that health-care providers should particularly support actors' psychological need fulfillment to facilitate their well-being (e.g. offering patients ways to fulfill their need for competence by letting them wash parts of their bodies themselves, giving family members opportunities to protect patient well-being to fulfill their need for competence). FLEs should be aware of the consequences of their own activities on other actors' needs to prevent negative effects and identify other opportunities to contribute to actor and network well-being (Findsrud et al., 2018). This recommendation is especially pertinent to health care, in which focal actor well-being depends heavily on how the care is provided because focal actors lack the knowledge to assess its technical quality (Horodnic et al., 2018). That is, the interaction between nurses and patients is critical for patient well-being (Anderson and Smith, 2018).
Balanced centricity arguably might not be realistically feasible in a highly complex service system featuring vulnerable actors. Based on a multi-actor approach, our findings suggest two managerial recommendations that could contribute to balanced centricity and that are generalizable to other healthcare encounters as well: grant control to vulnerable focal actors by assessing their needs and stimulate all network actors to participate in the co-creation of services.

\section{Grant control to vulnerable focal actors (patients)}

A key goal should be to identify and eliminate tensions among actors' needs, especially between vulnerable focal actors' (e.g. patients') need for autonomy and other actors' needs. Especially FLEs should be aware of their important role because they can provide vulnerable focal actors a sense of control by supporting them in the co-creation of services (Virlée et al., 2020). The data emphasize the importance of autonomy in relation to focal actors' well-being but also suggest the limits of such autonomy. Notably, focal actors' autonomy is constrained by their lack of choice, as might be caused when FLEs stick with routines to fulfill their own need for competence. For example, despite evidence that washing without water is at least as effective as in-bed baths with water and soap (Groven et al., 2017), several nurses expressed doubts about the effectiveness of washing without water and therefore continued to bathe patients with water and soap. These nurses also might have remained unaware of patients' preferences; many patients indicated they would rather receive baths provided without water.

Service managers can resolve such tensions between vulnerable focal actors' autonomy-based needs and FLEs' competence-based needs by encouraging frequent, active information exchanges. With respect to the in-bed bath, nurses might change their mind about washing without water if patients (actively or reactively) shared their preferences every time they were bathed. Several pieces of illustrative evidence also indicate that nurses feel more competent when patients share their preferences, which helps them deliver proper care. At the same time, patients gain control over the in-bed bath when they can share their preferences. Consequently, patients' and nurses' control balance better, which improves both actors' well-being (Black and Gallan, 2015). For other health-care encounters such as feeding patients or subscribing to medicine, health-care workers similarly might deviate from routines they personally find effective if they are aware of actors' preferences. If FLEs have a means to accommodate focal actors' preferences without jeopardizing their own need fulfillment (e.g. bathing body parts in a certain order), care providers will be more effective for both parties involved.

Balanced centricity, thus, could be enhanced if FLEs frequently collect information on focal actors' needs and deliver service accordingly, especially in tasks that they execute routinely but that also have a significant impact on the wellbeing of vulnerable focal actors. Service managers could facilitate information exchanges by training FLEs and by introducing supportive tools. For example, nurses could wear buttons that encourage patients to "Tell me what you need today" and thereby invite patients to share their preferences. Finally, when vulnerable focal actors cannot share preferences (e.g. cognitively impaired patients), other actors (e.g. TSMs 
such as family) should be involved more, which could improve the focal actors' autonomy and well-being (Johns and Davey, 2019).

\section{Stimulate all network actors to participate in the co-creation of} services

In health care, family involvement has the potential to contribute to network well-being, as suggested by previous research that defines health care as a team effort, involving patients, professional caregivers and families (McCollKennedy et al., 2017; Midtbust et al., 2018). Increased family (i.e. TSMs) involvement could contribute to all actors' needs. For FLEs, TSMs represent important information sources to learn about focal actors' preferences, so involving TSMs could fulfill FLEs' need for competence. At the same time, TSMs would have more opportunities to protect focal actor well-being and thereby fulfill their need for competence. Finally, this approach would enhance focal actors' autonomy because the TSM can match focal actors' preferences. Unfortunately though, in our study, family members expressed little knowledge about in-bed bathing processes.

This lack of knowledge might indicate a lack of communication among actors, which also can lead to imbalances (Verleye et al., 2017). Health-care managers should find ways to build co-creation cultures that "support all actors in actively participating in resource integration" (Sharma and Conduit, 2016, p. 439). For example, health-care managers could organize "nurse-for-a-day" meetings, in which family members join the nurse in performing care provision activities with the patient. During these interactions, all actors gain opportunities to discuss care preferences and identify potential tensions such as when family and nurses have opposing views on what is best for the patient (Midtbust et al., 2018).

Finally, this study encourages health-care managers to foster longitudinal (vs episodic) relationships primarily between patients and nurses but also between family members and nurses (Berry et al., 2020). Longitudinal relationships could be realized by assigning the same nurses to the same patients (and their families). Such an approach could help patients, nurses and family members gain better knowledge about each other's needs, which could be taken into account during key recurring service encounters such as in-bed baths. As a result, individual actor well-being and network well-being would increase. For example, patients' need for autonomy could be fulfilled if their preferences are met more often because of nurses' increased knowledge about these preferences; nurses' need for competence could be fulfilled if they know that they contributed to patient satisfaction with the in-bed bath and family members' need for competence could be fulfilled if they have a central nurse to talk to in order to protect patients' wellbeing.

\section{Limitations and further research}

This exploratory study offers a foundation for continued research that expands understanding of the interrelationships between actor and network well-being. The findings are particularly valuable for transformative systems in which wellbeing is critical such as health care. We focused on network actors that we deemed most relevant to in-bed bath service provision, namely, patients, nurses and families. Studies also could expand to include larger networks of other actors such as doctors, friends and support groups. Furthermore, the chosen context offers valuable insights into actors' needs and wellbeing and applying the model to other (health-care) services could be similarly insightful. Family members' involvement in in-bed bathing appears relatively minimal and patients generally are rather passive. Accordingly, it would be useful to apply this study's model to service settings in which actors are more involved and more willing to initiate the co-creation of services. Other applications could refer specifically to the impact of tensions across health-care encounters (e.g. how tensions during the in-bed bath affect subsequent health-care encounters such as receiving meals) and explore how actors cope with these tensions over time.

Finally, further research could address the influence of contextual factors on actors' needs. We note several contextual factors that appear to affect actors' need fulfillment, including health-care structures and institutions (e.g. morning bathing routines), resource availability (e.g. sufficient nurses) and technology adoption (e.g. washing without water). New technologies encourage the development of innovative services that can create beneficial outcomes for multiple actors (Patrício et al., 2018). In line with our argument that fulfilling all actors' psychological needs is critical to network well-being, we call for research that clarifies the influence of technological components within service systems on actors' psychological need fulfillment. In general, exploring the impact of contextual factors on actors' need fulfillment could facilitate the achievement of more balanced service systems.

\section{References}

Ahluwalia, S.C., Gill, T.M., Baker, D.I. and Fried, T.R. (2010), "Perspectives of older persons on bathing and bathing disability: a qualitative study", fournal of the American Geriatrics Society, Vol. 58 No. 3, pp. 450-456.

Alvesson, M. and Kärreman, D. (2007), "Constructing mystery: empirical matters in theory development", Academy of Management Review, Vol. 32 No. 4, pp. 1265-1281.

Anderson, S., Nasr, L. and Rayburn, S.W. (2018), "Transformative service research and service design: synergistic effects in health-care", The Service Industries fournal, Vol. 38 Nos 1/2, pp. 99-113.

Anderson, S.T. and Smith, J.S. (2018), "Understanding hospital quality: the case of cumulative and balanced quality", The Service Industries fournal, Vol. 38 Nos 3/4, pp. 182-200.

Baumeister, R.F. and Leary, M.R. (1995), "The need to belong: desire for interpersonal attachments as a fundamental human motivation", Psychological Bulletin, Vol. 117 No. 3, pp. 497-529.

Berry, L.L., Attai, D.J., Scammon, D.L. and Awdish, R.L.A. (2020), "When the aims and the ends of health-care misalign", Fournal of Service Research, pp. 1-25, available at: https://doi.org/10.1177/1094670520975150

Black, H.G. and Gallan, A.S. (2015), "Transformative service networks: cocreated value as well-being", The Service Industries fournal, Vol. 35 Nos 15/16, pp. 826-845.

Čaić, M., Odekerken-Schröder, G. and Mahr, D. (2018), "Service robots: value co-creation and co-destruction in 
elderly care networks", Fournal of Service Management, Vol. 29 No. 2, pp. 178-205.

Campbell, J.L., Quincy, C., Osserman, J. and Pedersen, O.K. (2013), "Coding in-depth semistructured interviews: problems of unitization and intercoder reliability and agreement”, Sociological Methods \& Research, Vol. 42 No. 3, pp. 294-320.

Davey, J. and Grönroos, C. (2019), "Health service literacy: complementary actor roles for transformative value cocreation", Fournal of Services Marketing, Vol. 33 No. 6, pp. 687-701, available at: https://doi:10.1108/JSM-09-20180272

Dean, A. and Indrianti, N. (2020), "Transformative service research at the BoP: the case of Etawa goat farmers in Indonesia", fournal of Services Marketing, Vol. 34 No. 5.

Deci, E.L. and Ryan, R.M. (2000), “The 'what' and 'why' of goal pursuits: human needs and the self-determination of behavior", Psychological Inquiry, Vol. 11 No. 4, pp. 227-268.

Downey, L. and Lloyd, H. (2008), "Bed bathing patients in hospital", Nursing Standard, Vol. 22 No. 34, pp. 35-40.

Engström, J. and Elg, M. (2015), "A self-determination theory perspective on customer participation in service development", fournal of Services Marketing, Vol. 29 Nos 6/7, pp. 511-521.

Falter, M. and Hadwich, K. (2020), "Customer service wellbeing: scale development and validation", The Service Industries fournal, Vol. 40 Nos 1/2, pp. 181-202.

Findsrud, R., Tronvoll, B. and Edvardsson, B. (2018), "Motivation: the missing driver for theorizing about resource integration", Marketing Theory, Vol. 18 No. 4, pp. 493-519.

Frow, P., Mccoll-Kennedy, J.R. and Payne, A. (2016), "Cocreation practices: their role in shaping a health-care ecosystem", Industrial Marketing Management, Vol. 56, pp. 24-39.

Gioia, D.A., Corley, K.G. and Hamilton, A.L. (2012), "Seeking qualitative rigor in inductive research: notes on the Gioia methodology", Organizational Research Methods, Vol. 16 No. 1, pp. 15-31.

Grönroos, C. and Voima, P. (2013), "Critical service logic: making sense of value creation and co-creation", fournal of the Academy of Marketing Science, Vol. 41 No. 2, pp. 133-150.

Groven, F.M.V., Zwakhalen, S.M.G., Odekerken-Schröder, G., Joosten, E.J.T. and Hamers, J.P.H. (2017), "How does washing without water perform compared to the traditional bed bath: a systematic review", BMC Geriatrics, Vol. 17 No. 1.

Gummesson, E. (2002), "Relationship marketing and a new economy: it's time for de-programming", fournal of Services Marketing, Vol. 16 No. 7, pp. 585-589.

Gummesson, E. (2005), "Qualitative research in marketing”, European fournal of Marketing, Vol. 39 Nos 3/4, pp. 309-327.

Gummesson, E. (2007), "Exit services marketing - enter service marketing", fournal of Customer Behaviour, Vol. 6 No. 2, pp. 113-141.

Gummesson, E. (2008), "Extending the service-dominant logic: from customer centricity to balanced centricity", Fournal of the Academy of Marketing Science, Vol. 36 No. 1, pp. 15-17.
Hillebrand, B., Driessen, P.H. and Koll, O. (2015), "Stakeholder marketing: theoretical foundations and required capablities", fournal of the Academy of Marketing Science, Vol. 43 No. 4, pp. 411-428.

Horodnic, A.V., Apetrei, A., Luca, F. and Ciobanu, C. (2018), "Rating health-care services: consumer satisfaction vs. health system performance", The Service Industries fournal, Vol. 38 Nos 13/14, pp. 974-994.

Johns, R. and Davey, J. (2019), "Introducing the transformative service mediator: value creation with vulnerable consumers", fournal of Services Marketing, Vol. 33 No. 1, pp. 5-15.

Kasser, V.G. and Ryan, R.M. (1999), "The relation of psychological needs for autonomy and relatedness to vitality, well-being, and mortality in a nursing home", fournal of Applied Social Psychology, Vol. 29 No. 5, pp. 935-954.

Kitson, A., Conroy, T., Kuluski, K., Locock, L. and Lyons, R. (2013), "Reclaiming and Redefining the Fundamentals of Care: nursing's Response to Meeting Patients' Basic Human Needs", Adelaide, South Australia: School of Nursing, the University of Adelaide.

Leo, W.W.C., Laud, G. and Chou, C.Y. (2019), "Service system well-being: conceptualising a holistic concep", fournal of Service Management, Vol. 30 No. 6, pp. 766-792.

Leroi-Werelds, S. (2019), "An update on customer value: state of the art, revised typology, and research agenda", fournal of Service Management, Vol. 30 No. 5.

McColl-Kennedy, J., Hogan, S.J., Witell, L. and Snyder, H. (2017), "Cocreative customer practices: effects of healthcare customer value cocreation practices on well-being", Fournal of Business Research, Vol. 70, pp. 55-66.

McColl-Kennedy, J.R., Vargo, S.L., Dagger, T.S., Sweeney, J. C. and Kasteren, Y.V. (2012), "Health-care customer value cocreation practice styles", fournal of Service Research, Vol. 15 No. 4, pp. 370-389.

Midtbust, M.H., Alnes, R.E., Gjengedal, E. and Lykkeslet, E. (2018), "A painful experience of limited understanding: health-care professionals' experiences with palliative care of people with severe dementia in Norwegian nursing homes", BMC Palliative Care, Vol. 17 No. 1.

Neghina, C., Bloemer, J., Van Birgelen, M. and Caniëls, M.C. J. (2017), "Consumer motives and willingness to cocreate in professional and generic services", fournal of Service Management, Vol. 28 No. 1, pp. 157-181.

Ng, S.C., Plewa, C. and Sweeney, J.C. (2016), "Professional service providers' resource integration styles (PRO-RIS): facilitating customer experiences", fournal of Service Research, Vol. 19 No. 4, pp. 380-395.

Oertzen, A., Odekerken-Schröder, G., Brax, S.A. and Mager, B. (2018), "Co-creating services - conceptual clarification, forms and outcomes", fournal of Service Management, Vol. 29 No. 4, pp. 641-679.

Osei-Frimpong, K. (2017), "Patient participatory behaviours in health-care service delivery", fournal of Service Theory and Practice, Vol. 27 No. 2, pp. 453-474.

Ostrom, A.L., Parasuraman, A., Bowen, D.E., Patrício, L. and Voss, C.A. (2015), "Service research priorities in a rapidly changing context", fournal of Service Research, Vol. 18 No. 2, pp. 127-159. 
Pandit, N.R. (1996), "The creation of theory: a recent application of the grounded theory method", fQualitative Report, Vol. 2 No. 4, pp. 1-15.

Patrício, L., Gustafsson, A. and Fisk, R. (2018), "Upframing service design and innovation for research impact", fournal of Service Research, Vol. 21 No. 1, pp. 3-16.

Pinho, N., Beirão, G., Patrício, L. and Fisk, R.P. (2014), "Understanding value co-creation in complex services with many actors", Fournal of Service Management, Vol. 25 No. 4, pp. 470-493.

Plé, L. and Cáceres, R.C. (2010), "Not always co-creation: introducing interactional co-destruction of value in servicedominant logic", Fournal of Services Marketing, Vol. 24 No. 6, pp. 430-437.

Quero, M.J. and Ventura, R. (2015), "The role of balanced centricity in the spanish creative industries adopting a crowdfunding organisational model", Fournal of Service Theory and Practice, Vol. 25 No. 2, pp. 122-139.

Reypens, C., Lievens, A. and Blazevic, V. (2016), "Leveraging value in mutli-stakeholder innovation networks: a process framework for value co-creation and capture", Industrial Marketing Management, Vol. 56, pp. 40-50.

Rosenbaum, M.S. (2015), "Transformative service research: research that matters", The Service Industries fournal, Vol. 35 No. 15-16, pp. 801-805.

Ryan, R.M. and Deci, E.L. (2000), "Self-determination theory and the facilitation of intrinsic motivation, social development, and well-being", American Psychologist, Vol. 55 No. 1, pp. 68-78.

Rynes, S. and Gephart, R.P. (2004), "From the editors: qualitative research and the 'academy of management journal'", Academy of Mangement fournal, Vol. 47 No. 4, pp. 254-462.

Saunders, B., Sim, J., Kingstone, T., Baker, S., Waterfield, J., Bartlam, B., Burroughs, H. and Jinks, C. (2018), "Saturation in qualitative research: exploring its conceptualization and operationalization", Quality $\mathcal{E}$ Quantity, Vol. 52 No. 4, pp. 1893-1907.

Sharma, S. and Conduit, J. (2016), "Cocreation culture in health-care organizations", Fournal of Service Research, Vol. 19 No. 4, pp. 438-457.

Sharma, S., Conduit, J. and Hill, S.R. (2017), "Hedonic and eudaimonic well-being outcomes from co-creation roles: a study of vulnerable customers", Fournal of Services Marketing, Vol. 31 No. 4/5, pp. 397-411.

Spiggle, S. (1994), "Analysis and interpretation of qualitative data in consumer research", Fournal of Consumer Research, Vol. 21 No. 3, pp. 491-503.

Suárez-Álvarez, L., Suárez-Vázquez, A. and del Río-Lanza, A. (2020), "Companion cocreation: improving health service encounters of the elderly", Fournal of Services Marketing, Vol. 35 No. 1, available at: https://doi:10.1108/JSM-092019-0367
Sweeney, J.C., Dagger, T.S. and McColl-Kennedy, J.R. (2015), "Customer effort in value cocreation: improving quality of life and behavioral intentions of health-care customers", Fournal of Service Research, Vol. 18 No. 3, pp. 318-335.

Taiminen, H., Taiminen, K. and Munnukka, J. (2020), "Enabling transformative value creation through online weight loss services", fournal of Services Marketing, Vol. 34 No. 6, pp. 797-808, available at: https://doi:10.1108/JSM05-2019-0191

Vargo, S.L., Akaka, M.A. and Vaughan, C.M. (2017), "Conceptualizing value: a service-ecosystem view", fournal of Creating Value, Vol. 3 No. 2, pp. 1-8.

Vargo, S.L. and Lusch, R.F. (2004), "Evolving to a new dominant logic for marketing", fournal of Marketing, Vol. 68 No. 1, pp. 1-17.

Vargo, S.L. and Lusch, R.F. (2018), The SAGE Handbook of Service-Dominant Logic, SAGE Publications Inc.

Verleye, K., Jaakkola, E., Hodgkinson, I.R., Jun, G.T., Odekerken-Schröder, G. and Quist, J. (2017), "What causes imbalance in complex service networks? Evidence from a public health service", fournal of Service Management, Vol. 28 No. 1, pp. 34-56.

Virlée, J., Van Riel, A.C.R. and Hammedi, W. (2020), "Health literacy and its effects on well-being: how vulnerable healthcare service users integrate online resources", fournal of Services Marketing, Vol. 34 No. 5, pp. 697-715.

\section{Appendix. Script interview with patients (nurses/family members)}

- Can you tell me something about your day so far?

- You told me, you were (the patient was/your family member was) bathed today. Is it important to be bathed and why?

- Can you describe the in-bed bath for me?*

- What are the consequences of the in-bed bath for (the patient/your family member) you?*

- Are you satisfied with the in-bed bath (of the patient/your family member)?

- What is the most important about the in-bed bath (of the patient/your family member)?*

${ }^{*}$ Laddering/probing was used to ask, for example:

- Is that (certain in-bed bath activity) important for you?

- Why is it important for you?

- Who was involved? What did this person do?

- Would it have been different if this person was not involved?

\section{Corresponding author}

Fabian Groven can be contacted at: f.groven@, maastrichtuniversity.nl 